Esta obra está bajo una Licencia Creative Commons Atribución-NoComercial-Compartirlgual 4.0 Internacional

(c) (1) (2) (2)

La construcción de un problema público. Identidad, gramática y acción colectiva

Vanesa Noemí Herrero

DOI: https://doi.org/10.24215/16696581e215

\title{
La construcción de un problema público. Identidad, gramática y acción colectiva
}

\section{The construction of a public problem. Identity, grammar and collective action}

\author{
Vanesa Noemí Herrero herrerovanesan@gmail.com \\ https://orcid.org/0000-0003-0367-3211
}

Laboratorio Movimientos Sociales y Condiciones de Vida; Facultad Trabajo Social; Universidad Nacional de La Plata (Argentina) 


\section{Resumen}

En este trabajo propongo analizar la construcción un problema público a partir de la experiencia colectiva de aquellas personas que utilizan la recolección, clasificación y venta de materiales reciclables como modo de subsistencia.

Interesa demostrar cómo desde la masificación del fenómeno del cartoneo a finales de la década de los 90 hasta la actualidad, a través de diferentes modalidades de acción colectiva, representación y estrategias en el espacio público se obtuvo como resultado la conversión de un problema particular a un problema público. Este problema refiere a las condiciones de trabajo, el reconocimiento de la actividad de recuperación de residuos y las condiciones de vida de miles de sujetos dedicados al cartón, el papel y la botella.

Palabras clave: espacio público, acción colectiva, identidad, gramática.

\section{Abstrac}

In this article, I propose to analyze the construction of a public problem based on the collective experience of those people who use the collection, sorting, and sale of recyclable materials as a way to subsistence.

It is interesting to demonstrate how from the massification of the cartoneo phenomenon at the end of the 90s until now, through different modalities of collective action, representation and strategies in Public space were obtained as a result of the conversion of a particular problem to a public problem.

This problem refers to the working conditions, the recognition of the recovery activity of waste and living conditions of thousands of subjects dedicated to cardboard, paper, and bottle.

Keywords: public space, collective action, identity, grammar.

\section{Introducción}

La actividad de recuperación informal de residuos es de vieja tradición, aunque adquiere características particulares en los últimos años (Eduardo Anguita, 2003), también conocida como recolección informal de residuos por cuanto no es parte de la gestión de residuos oficial tanto en Argentina, como en diversos países de América Latina. 
Defino como cartonero a aquel sujeto que de forma individual, familiar o colectiva recupera de manera informal (por fuera del circuito formal de recolección de la basura urbana), los residuos urbanos para su posterior clasificación y comercialización en diversas formas (Débora Gorban, 2014; Pablo Schamber \& Francisco Suárez, 2007, 2011).

A finales de la década de los 90, en inmediaciones de la crisis del 2001 y posterior a la devaluación el número de personas dedicadas es cartonear creció considerablemente. Si bien no existen cifras oficiales la Federación Argentina de Cartoneros y Recicladores estima que en Argentina hay 500.000 cartoneros, cartoneras, carreros y carreras. En el año 2001 esta cifra se estimaba en 30.000 .

Es a partir de la masificación del fenómeno que se comienzan a construir modalidades de organización, logrando convertir una tarea solitaria y de subsistencia en un trabajo colectivo y problema de agenda pública (Herrero 2016; Herrero \& Schettini 2017; Herrero 2018)

Este proceso ha sido y es producto de la acción colectiva como herramienta mediatizadora. Reconstruiré en este trabajo tres dimensiones que considero que confluyeron a este objetivo:

-La construcción de una identidad cartonera que se identifica en el pasaje de la figura del ciruja a la de cartonero.

-La gramática y narrativa que consolidaron las organizaciones de cartoneros para instalar el problema.

-Las acciones colectivas que sostuvieron y sostienen en base a los argumentos expuestos y el efecto de las mismas.

La primera y la segunda dimensión refieren a aspectos globales del proceso de colectivización (Herrero \& Schettini 2017; Herrero 2018)

El tercer eje será abordado a través del problema local de investigación que se desarrolla en el distrito de La Plata. A modo de ejemplificación analizaré específicamente una serie de hechos en un periodo de tiempo- 2017-2017 para poder comprender cómo esta gramática juega en la gestión del conflicto, durante el periodo 2015-2017.

Los resultados obtenidos devienen de datos recolectados en el campo principalmente a través de la observación no participante, charlas informales y entrevistas semi-estructuradas. Incorporo fuentes secundarias pertinentes para esta ocasión: notas periodísticas en portales online de medios locales, posteos en redes sociales de cuentas oficiales de la organización estudiada (facebook, instagram), información y declaraciones en páginas web oficiales la Confederación de Trabajadores de la Economía Popular (CTEP) y Federación Argentina de Cartonero y Recicladores (FACyR). 
No somos cirujas, somos cartoneros. Estereotipos, diferencia e identidad.

Como plantea Hall (2010) lo que decimos y queremos decir se modifica por la interacción y el interjuego con otra persona. <El significado se origina a través de la diferencia entre los participantes en cualquier diálogo (...) el "Otro" es esencial para el significado (pág. 420)>. Pero a veces pareciera que el otro no tiene voz propia, y es simplemente nombrado.

Antes de ser llamados cartoneros, carreros, recicladores o recuperadores las personas que viven de la basura eran identificados con otras palabras menos afortunadas. En México los llaman pepenadores, en Brasil catadores; en Perú moscas, en Paraguay gancheros; en Argentina, cirujas. Algunos de estos nombres cargan más estigmas que otros (Schamber \& Suárez, 2007, 2011). El ganchero de Uruguay, aquel que, con un gancho, que se convierte en una extensión de su mano, agarra lo que podía de los basurales, grandes usina y vaciaderos. En Brasil el catador, sujeto de la calle, un sujeto de nadie. En Argentina fueron conocidos como cirujas, quemeros, raneros o botelleros.

En paralelo con la conformación de grandes centros industriales y el proceso de urbanización de zonas antes no tan poblados, el problema de la higiene urbana demandó medidas urgentes en la organización del incipiente Estado-Nación en Argentina. Anteriormente-en la época colonial- cada persona o familia debía resolver de manera individual qué hacer con los desechos que generaba (Schamber y Suárez 2007, Débora Gorban 2014). Las modalidades más comunes eran el entierro o la quema en los patios traseros de las viviendas.

Hacia 1870 se asigna un lugar oficial como vaciadero municipal en la zona Sur de Bs As para la disposición y quema de los residuos a cielo abierto, lo que trajo variados problemas de contaminación, higiene y salud (Schamber y Suárez 2002). Lo llamaban la Quema, y es alrededor de este vaciadero que se conformó el denominado Pueblo de Ranas: un aglomerado de casas hechas de latas de kerosene enteras, abandonadas, vacías y luego rellenadas con barro. La gente que vivía allí basaba su subsistencia en el aprovechamiento de lo volcado en el lugar. Surge así, la figura tradicional del ranero, quemero o ciruja. Es así, que esta actividad se origina a fines del siglo XIX, paralelamente al desarrollo de la ciudad.

Como plantea Gorban 2014:

El ranero, el ciruja y el quemero representaban los segmentos más relegados de la sociedad. $<$ Estos sujetos parecían adquirir los mismos rasgos que los basurales de los cuales se servían y donde vivían (...) percibidos de la misma manera que los desechos que recolectaban > (pág. 43)

Los estereotipos sobre estos sujetos se pueden apreciar en este fragmento extraído por Verónica Paiva y Mariano Parelman (2008; 6) de un archivo del año 1905. 
Es necesario que entren en un cuartujo de estos, donde muchas veces el médico para ver á un enfermo ha tenido que hacer destechar para hacer la visita: donde se ha llegado el caso de encontrar cerdos en el mismo cuarto del enfermo; es necesario entrar en estas viviendas para tener una idea del desaseo y de las acumulaciones de inmundicias que en ellas se hacen. Muchos de los individuos que trabajan en la "quema" y sus familias se visten y comen de lo que recogen en las basuras (Piñero 1905: 26)

Para dar otro ejemplo expongo fragmentos de dos canciones populares que han personificado a estos dos sujetos, exaltando los rasgos característicos del ciruja.

Una es la canción Botellero, interpretada por Jorge Larralde:

\author{
Botellero!!! (...) Montón de andrajo y voz de vino \\ parecía nacido en los camino \\ la carretilla con una soga \\ paseaba por las calles su rueda floja. \\ De pelo largo, barba crecida \\ gritaba a todo pecho, nadie lo oía. \\ A mi memoria, llega clarito \\ triste grito de zanja su viejo grito.
}

Con el mismo título el grupo de cumbia villera Pibes Chorros, popularizo estas estrofas:
Revolviendo en los baldíos
cinco perros van conmigo
en mi carro voy contento
escabiando vino suelto
Botellero botellero
me gusta el faso me gusta el vino
botellero botellero
tomo del blanco tomo del tinto
yo me paso los días tomándome la vida.

Podemos ver las connotaciones negativas respecto del ciruja incluso trascripta en símbolos de la cultura popular como lo es el tango y la cumbia villera. Ciertos rasgos específicos determinan las características generales de estos sujetos, condenándolos al estigma y la exclusión (Stuart Hall 2010). Hall retoma a (Dyer 1977) para definir lo que es un estereotipo. 
Un sistema de estereotipos sociales se refiere a lo que está por dentro y fuera de los límites de la normalidad [es decir, la conducta que se acepta como 'normal' en cualquier cultura] (...) los estereotipos son también más rígidos que los tipos sociales [...] Los límites [...] deben quedar claramente delineados y también los estereotipos, uno de los mecanismos del mantenimiento de límites, son característicamente fijos, inalterables, definidos.

El botellero o ciruja, es estereotipado con características siempre similares: marginal, sucio, andrajoso, irresponsable, alcohólico, errante. Sostengo, que la primera forma de diferenciarse de otros grupos del cartonero, se funda en apartarse de estos grupos. El significado se construye a través de la diferencia con el otro, a través de distinguirse y desplazar mecanismos que pueden ir desde la identificación, la asimilación, el desprestigio o la aniquilación (Hall 2010) Transcribo aquí tres pequeños fragmentos de entrevistas a cartoneros, producto de mi trabajo de campo y otro extraído del trabajo de Gorban (2014), que dan cuenta de esta diferencia:

\footnotetext{
Se dice cartonero, reciclador...también comerciante...ciruja no. Se dice lo que es. Ciruja es un croto, un caminante. A vos te tiene que gustar recuperar, juntar antigüedades...no es cualquier cosa. No es como el ciruja, tiene sus trucos" (Entrevista a cartonero, La Plata)
}

\begin{abstract}
Ciruja no soy, pero si cartonera (...) un ciruja es aquel que no se ocupa de su casa ni de sus hijos y aquel que vive en la calle por la necesidad o la circunstancia. No tiene techo. No tiene responsabilidad" (Gorban 2014: pág. 23)

Nos hacemos conocidos y ya de confianza, me entendés sea... ya que ellos saben que vos les vas a llevar las bolsas y que no le vas a romper la bolsa y que llevas sin ningún problema. $Y$ eso es lo que pasa. $Y$ bueno en todos los lugares vos le pedís y ellos te lo guardan (Carrero, La Plata)
\end{abstract}

Aquí vemos como un grupo se constituye por los límites, diferenciándose de otro. Los cartoneros hacen un esfuerzo constante por desprenderse de esa especie de estigma popular que los cirujas le han legado. Un grupo puede estigmatizar a otro efectivamente sólo cuando solo mientras esté establecido en posiciones de poder de las cuales el grupo estigmatizado se encuentran excluidos (Norbet Elías 1998: 93)

No quiere decir que renieguen del cirujeo pero sí de aquellas connotaciones negativas que los cirujas les legaron. El cartonero se presenta como un trabajador, que sale a cartonear para dar de comer a su familia antes que salir a robar.

El cartonero construye una subjetividad y una identidad que le permite dignificarse. Así, el recuperador urbano no anhela ser ciruja, anhela ser trabajador. Ataque 77 popularizó el tema 
Cartonero donde se registran las características del mismo: una persona pobre pero honrada y honesta, que hace lo que hace para sobrevivir y no es reconocido por su trabajo.

Qué paradoja que teniendo motivos de sobra para ir a robar

Al delito yo lo esquivo inventando trabajo en donde no hay

y encima de rebote soy la alternativa ecológica

reciclando lo que todos tiran los desechos de la sociedad.

Los mismos sujetos en cuestión, en un proceso de re significación de su tarea, buscaron identificarse con aquellas denominaciones menos cargadas de sentidos, más alejadas de los prejuicios sociales, permitiéndoles ser percibidos de otra manera, alejados de la identificación con la basura y con las imágenes de vagos, delincuentes y malandros. (Gorban 2014:43). En esta gramática es que surgue este nuevo sujeto colectivo.

En esta primera descripción encontramos las pistas que luego desencadenan en procesos de colectivos y organizativos. Es a partir de la construcción de un nosotros que fue posible pasar de estas particularidades a la publicidad de un problema.

La instalación de un problema en el espacio público a través de la organización colectiva.

Daniel Cefai (2002) retomando a Habermans (1962) define

el espacio púbico como un lugar de mediación entre los poderes públicos, la sociedad política, la sociedad civil y los medios de comunicación. [...]) Los procesos de opinión pública y de acción colectiva que engendran los mundos sociales crean la cosa pública (Cefai 2002; pag.7).

A partir de fines de los 90 y luego de la crisis del 2001, la ciudad de Buenos Aires es testigo de la irrupción masiva de hombres, mujeres, niños, ancianos y familias enteras que transitaban las calles revolviendo la basura para generar algún ingreso con sus carros tirados a mano, bicicletas o caballos. Esta misma escena se repetiría en otros puntos de la provincia y del país durante aquellos vertiginosos años. (Eduardo Anguita 2001; Gorban 2014; Paiva 2011; Schamber y Suárez 2007).

Este fenómeno que parecía ser una novedad pasajera fue cubierto por medios a nivel nacional, local y regional generando opiniones de diverso tipo, así como expresiones que iban desde la lástima, la compasión, la vergüenza, el enojo, la indignación hasta la discriminación, la estigmatización y la criminalización (1). 
La realización del documental Cartoneros de Villa Itati (2003) fue una suerte de visibilizacion de la cara más cruel de la crisis que se atravesó en esos años. Narraba en las voces de sus protagonistas, en crudas imágenes mostraba la vida de los cartoneros y cartoneras de una villa de Quilmes. En el documental se resaltaba claramente el espíritu de dignidad y lucha constante de estos sujetos lo que ocasionó un impacto positivo en general. (Verón, 1999).

Los cartoneros y carreros tanto Argentina como en diversas experiencias en América Latina han optado por la organización colectiva, ya sea constituyendo cooperativas, uniones, asociaciones, confederaciones para ser representados en sus demandas. Esta organización se ancló en una lucha por el reconocimiento de su actividad, mejores condiciones de trabajo y de vida (Mariana Dimarco 2005; Nicolás Menéndez 2013; Nicolás Villanova 2014).

En lo que sigue internare demostrar como la combinación de repertorios de acción (Sidney Tarrow, 1997) y repertorios de argumentación (Cefai ,2002) posibilito que estos actores asumieran y difieran su situación como problemática en la arena pública.

Un ejemplo paradigmático fue el Tren Blanco, un servicio de ferrocarril espacial para cartoneros de la empresa de TBA (Transporte Buenos Aires) que funcionó entre los años 1999 y 2007 (2). Frente a amenazas de expulsión de los vagones del tren común, los cartoneros se organizaron con un sistema de delegados, asambleas y junta de firmas a fin de obtener una solución (Gorban 2014; Paiva 2011). En el año 1999, la empresa decidió designar dicha unidad para el transporte de los recuperadores. Los viajes se realizaban condiciones insalubres y riesgosas en las que realizan la actividad y se transportaban en los furgones del tren, sufrían permanente acoso por parte de la policía federal que llevaba a cabo prácticas como el cobro de coimas, secuestro de carros y caballos y detenciones en la vía pública. Se vivieron momentos de tensión por acciones espontáneas de los cartoneros como la quema de Comisarías y los escraches obteniendo como respuesta del Estado la represión y el desalojo.

Tras años de conflicto la empresa Transporte Buenos Aires decidió poner fin a este servicio. A continuación, las declaraciones de la empresa para Página 12 en el año 2007.

TBA no puede seguir brindando en la línea Mitre el servicio de trenes especiales a cartoneros bajo las actuales condiciones en las que se está haciendo y los cartoneros deberán entender que es riesgoso para ellos mismos continuar con la utilización del tren cartonero para transportar sus carros"

A las 23.15 un grupo de cartoneros que descendió con sus carros en la estación San Fernando, antes de bajar de la formación, encendió fuego un tacho de basura en el último coche. Al llegar el tren a la estación de Carupá, el fuego ya había consumido parte de este coche y comenzó a propagarse por el interior de toda la formación", relató TBA. 
Además, provocó la inutilización de esta formación ya que resultaron con daño total cinco coches, "y esto equivale a una pérdida económica de 7.500.000 de pesos, que deberá afrontar el Estado Nacional", sostuvo la empresa.

El Tren Blanco fue un punta pie para las modalidades de organización que se consolidarían posteriormente. En el año 2002 se realizo en la legislatura porteña la jornada de debate El trabajo no es basura donde participaron funcionarios públicos, militantes de organizaciones sociales, cartoneros, empresarios de la industria del reciclado y personajes de la sociedad civil. Es a partir de ese eslogan y otros como trabajar en el carro no es delito, reciclado por la inclusión social o la auto definición como trabajadores de la economía popular que los cartoneros y cartoneras a lo largo y ancho del país fueron construyendo sus demandas, exigiendo tanto a funcionarios públicos como a la sociedad civil en general el reconocimiento de su labor.

En este sentido la disputa de los cartoneros por la Gestión Integral de Residuos Sólidos Urbanos (GIRSU) se convirtió en la estrategia principal para convalidarse y desplegarse en la arena pública a través de acciones de disputa por los bienes públicos (Cefai 2002):

[...] la idea de arena pública como el lugar donde se despliegan las acciones que realizan los protagonistas y espectadores de un problema. Por otra parte una arena publica es también una arena social donde están en juego los bienes públicos (Cefai 2002; p.6)

Una arena social es para A. Strauss, un teatro de acciones conjuntas, coordinadas y concertadas, y por lo tanto teatro de competiciones, conflictos y controversias, donde los individuos y los colectivos se encuentran alrededor de cuestiones compartidas, arreglan situaciones problemáticas, elaboran programas de acciones, se enfrentan estrategias de interés, se comprometen en transacciones de todo tipo (Cefai 2002;p.7)

En el año 2002 se logro el reconocimiento legal de la figura de Recuperador Urbano (RU) a través de la Ley de Recuperadores Urbanos oㅜ 992 de la Ciudad de Buenos Aires que legalizó la actividad, derogando la ordenanza № 33.581 del periodo militar que prohibía el cirujeo. Esta ley se replico en varios municipios del país, teniendo en La Plata su parafraseo con la Ordenanza Municipal 10.061/09.

La gramática de las organizaciones de cartoneras, carreros y recicladores

Las formas de experiencia, opinión y de acción pública no dejan de instituirse una vez instalado el problema. La presentación de argumentos es un trabajo cognitivo y político permanente en las organizaciones sociales y políticas, que construye una relación entre pasado, presente y futuro (Chatearuraynaud; 2004).

Question, Vol. 1, N. ${ }^{\circ}$ 64, octubre-diciembre 2019. ISSN 1669-6581

Instituto de Investigaciones en Comunicación | Facultad de Periodismo y Comunicación Social | Universidad Nacional de La Plata La Plata | Buenos Aires | Argentina

Página 9 de 21 
Natalia Natalucci (2001) identifica la noción de gramática en el marco de la obra del filósofo Ludwing Wittgenstein. Diferencia tres acepciones del término en relación a la teoría de la movilización. Estos son a) la gramática como performatividad política de la acción, donde el estudio se orienta a una perspectiva pragmatista; b) la gramática como estructura motivacional de los sujetos implicados; lo que habilita un enfoque fenomenológico; y c) la gramática como estructura organizativa de los movimientos sociales, en clave de la movilización de recursos.

A fines de este trabajo se considera pertinente la primera y la segunda acepción. La primera refiere a la gramática política como

un juego de reglas no escritas que delimita, por un lado, las pautas de interacción de los sujetos; y por otro, las combinaciones de acciones para coordinar, articular e impulsar intervenciones públicas, acciones que se dirijan a cuestionar, transformar o ratificar el orden social (Natalucci 2011, pág. 7).

La segunda versa sobre los motivos que ligan la acción a la situación y a un repertorio de argumentos, justificaciones y marcos para la interpretación de las acciones propias y de los otros (pag.7).

En el caso de estudio el conjunto de las acciones e intervenciones públicas realizadas por el colectivo cartonero se asienta sobre la base de un repertorio de argumentos y marcos de significación. Como gramática, la acción y la argumentación se condensan en la arena pública a fin de gestionar los conflictos emergentes.

se conformaron de tres organizaciones de connotación política y social que se apropiaron de las demandas cartoneras para sostener el debate: la FACyR (Federación Argentina de Cartoneros y Recicladores), la CTEP (Confederación de Trabajadores de la Economía Popular) y el MTE (Movimiento de Trabajadores Excluidos).

La FACyR se enuncia en su sitio oficial como una herramienta gremial reivindicativa que los trabajadores crean para la defensa de los derechos y el reconocimiento del valor ambiental y social de su labor (4). Tanto el MTE como la CTEP se inscriben en el nuevo movimiento de la economía popular bajo a la consigna Tierra, Techo y Trabajo difundida por personajes político relevantes y la iglesia católica papista. Actualmente la CTEP agrupa trabajadores y trabajadoras de ramas como la textil, la rural (pequeños productores) feriantes, construcción, infraestructura social, vendedores ambulantes y cartoneros.

De esta manera la FACyR presenta a los cartoneros en su página oficial:

Excluidos y a la vez explotados, perseguidos e incomprendidos, los trabajadores cartoneros construimos, de a poco, organización y conciencia en algunas ciudades del país y, en algunos 
casos, apoyo y reconocimiento estatal. Sin embargo, en la República Argentina el cartonero sigue siendo un actor principalmente informal, su actividad está expuesta a un alto riesgo por falta de condiciones mínimas de higiene y seguridad, plagada de trabajo infantil, inmerso en ignominiosas situaciones de sobreexplotación y excluida del accionar integrador del Estado argentino.

Podemos enumerar tres argumentos principales que en el despliegue del colectivo cartonero a través de estas organizaciones:

-La ineficiencia del Estado a nivel municipal para la Gestión de Residuos Sólidos Urbanos. Los cartoneros, cartoneras y las organizaciones que los acompañaron denunciaron la grave situación de la basura urbana a pesar de los contratos millonarios que el Estado mantiene con empresas privadas a las que tildaron de corruptas y explotadoras. Esto se avaló con informes ambientales que demostraron la cantidad de disposición final de la basura, la ausencia de políticas de educación para la separación de residuos, los altos grados de contaminación y la existencia de dos mil basurales a cielo abierto en todo el país (3).

-El enfoque ambientalista y la rentabilidad del reciclado para los Estados latinoamericanos. Como analizan Suarez (2007) y Villanova (2015) el crecimiento de la industria del reciclaje está ligado a dos fenómenos: el enfoque ambientalista y el incremento de los precios de materiales reciclables luego de la devaluación de 2001. Los cartoneros realizan una labor ambiental importantísima al disminuir el volumen de material enterrado y fomentar la industria nacional del reciclado.

-El cartoneo o recuperación de residuos como un trabajo digno dentro de las opciones de supervivencia. La generación de ingresos para familias de los sectores más vulnerables a través de la actividad es lo que se denomina Reciclado por la inclusión social. El reconocimiento del trabajo que realizan los cartoneros por parte del Estado al incluirlos en la GIRSU genera fuentes de trabajo para sectores que lo han perdido, en lo que luego se enmarco como la economía popular.

En estos argumentos claramente pudieron diferenciar e instalar los roles identificados por Cefai (2002) para disputar una política que los integre. Estos son: los responsables (el Estado y funcionarios públicos), culpables (Estados, empresas que gestionan la GIRSU, industrial del reciclaje), justicieros (colectivo de identificación) y beneficiarios (familias cartoneras y la población urbana). Un problema público se publicita entonces cuando se vuelve sensible, cuando se inscribe en un espacio argumentativo y da lugar a diferentes especies de relatos (configuración dramática, retórica y narrativa).

Podemos ver en esta narrativa que la gestión del conflicto implicó por un lado abrir una relación de confrontación entre trabajadores no reconocidos en su labor, dignificados a través del 
trabajo y un Estado deficiente en la gestión de residuos en compañía de industrias que generan riqueza en base a la explotación de recuperadores informales. Se construye esa palabra adversativa de la que habla Verón (1999), que da forma a partir de un colectivo identificado a un enemigo, a un destinatario y a un paradestinatario.

Esto lo que permite es la visibilización del conflicto a partir de la demarcación de un espacio público en disputa. En el siguiente apartado a partir de un ejemplo concreto analizaremos la relación intrínseca entre el repertorio de acciones colectivas y los repertorios de argumentación

Acciones colectivas de protesta, arena pública y argumentación.

Las acciones colectivas realizadas por la organización -MTE CARTONEROS LA PLATAseleccionada son comprendidas como acciones públicas y políticas, principalmente de protesta e irrupción en el espacio público. Gabriel Nardacchione (2005, pág. 369) las caracteriza como aquellas acciones que surgen informalmente en la esfera pública como respuesta a una disrupción en la comunicación entre particulares y los poderes públicos. Se dirigen hacia un público abierto y tienen características particulares entre las cuales menciona la construcción de un nosotros, la acción como dispositivo de fuerza y la diferenciación en tanto colectivo identificado que proclama ser reconocido en la esfera pública.

En el año 2015 el proceso de organización colectiva de carreros y cartoneros (5) se gestó en el distrito de la Plata a partir la convocatoria del MTE hacia los cartoneros que no se encontraban organizados. Esto modificó el escenario de conflicto que se venía atravesando desde hace años con el Municipio y otros actores. He estudiado la problemática cartonera en la región desde el año 2012. Desde ese entonces ya existían conflictos entre pequeñas organizaciones de cartoneros y cooperativas pero su publicitación era escasa sin contar con la fuerza necesaria para instalar el problema (Herrero \& Schettini 2017; Herrero 2018)

Sostengo que esta organización política funcionó y funciona como mediatizadora entre los trabajadores cartoneros y otros actores del Estado y la sociedad civil. Mediatización entendida como un proceso presente en todo vínculo interpersonal medie o no un dispositivo tecnológico (Hjarvard; 2016).

Como he mencionado antes, se puso en marcha un proceso de identificación colectiva en un campo discursivo específico. Una de las primeras estrategias comunicativas del movimiento fue rescatar la figura de un referente carrero de la ciudad con el cual los nuevos miembros del colectivo se identificarán (Verón 1999). Este referente fue clave, ya que presentó desde un primer momento un discurso que llamaba a los y las cartoneras a sumarse a la organización colectiva para mejorar sus condiciones de trabajo y de vida. 
El mecanismo asambleario se presentó como otra estrategia de comunicación interna, nexo entre la argumentación y la acción colectiva. Se llevaron a cabo acciones de promoción y difusión en el derecho al trabajo y la obtención de recursos, negociaciones con funcionarios públicos y a nivel nacional la movilización junto con otros movimientos que permitió por ejemplo la sanción de la Ley de Emergencia Social en el año 2016. En los barrios se registro la construcción de merenderos y guarderías, programas de alfabetización, campañas de promoción de la salud, jornadas de desparasitación y vacunación de caballos, pintadas y arreglos de carros, relevamiento barrial, mejora de infraestructura y vivienda entre otros.

Durante el periodo 2015-2017 se realizaron cortes y movilizaciones prácticamente todos los meses. Las movilizaciones se decidían en asambleas y se realizaban con una frecuencia de una vez por mes aproximadamente ya que tras ser recibidos por los funcionarios municipales con la promesa de oír sus demandas, se establecían acuerdos que no se concretaban (Herrero 2016)

Tanto en registros locales como en registros de campo se observa un ida y vuelta constante entre acusaciones de la organización y declaración de funcionarios municipales afirmando su disposición al dialogo, aunque en la práctica no recibieran a los manifestantes. En ese sentido la organización denuncio esta situación en diversos medios locales (ver fuentes periodísticas) y posteo cada una de las acciones llevadas a cabo acompañada de los argumentos antes identificados. Trascribo algunos ejemplos:

MTE La Plata, Berisso, Ensenada 15 de diciembre de 2016 En el día de hoy nos movilizamos a la Municipalidad a exigir que se termine la persecución a los carreros y que las empresas privadas no se lleven el material del que vivimos. Fuimos atendidos por los funcionarios Juan Ayerra de Espacios Públicos, Rubén Casanova de Desarrollo Social, Dolores Oliva de Protección Animal, Daniel Pique de Seguridad y el concejal Julio Irurueta. Después de más de un año de estar en la calle, la Municipalidad de La Plata se comprometió a iniciar una transición donde no se nos persiga, para poder discutir en marzo un sistema de reciclado con inclusión social en base al proyecto piloto que presentamos hace meses.

MTE La Plata, Berisso, Ensenada 31 de mayo de 2016 El 17 de mayo, Día Mundial del Reciclaje, salimos a la calle a exigirle al Municipio el reconocimiento de nuestro trabajo y a denunciar que el nuevo convenio millonario con Esur nos deja sin el material que recuperamos de las calles. 
MTE La Plata, Berisso, Ensenada 31 de julio de 2016 . Compartimos un contra-spot que hicimos contestando a los que está difundiendo el Municipio. En sus campañas invisibilizan el trabajo que realizamos y mienten acerca del tratamiento de los residuos sólidos. ¡SIN CARTONEROS NO HAY RECICLADO!

MTE La Plata, Berisso, Ensenada 27 de junio de 2017 Hoy nos movilizamos por nuestros derechos y nuestro salario digno, mientras muchos están con los carguitos y las encuestas, las y los trabajadores de la economía popular salimos a pelear por nuestros derechos.

MTE La Plata, Berisso, Ensenada 3 de octubre de 2017 Hoy una vez más , nos movilizamos y reclamamos ser reconocidos como trabajadores, el Intendente Julio Garro nos invisibiliza y prefiere privatizar la recolección de nuestro cartón, cartón con el cual le damos de comer a nuestros niñitos y niñitas. Esperamos pronta respuesta \#TIERRATECHOTRABAJO \#SINCARTONEROSNOHAYBASURAO

Desde la municipalidad se argumentaba la necesidad de terminar con la tracción a sangre animal -polémica recrudecida por las asociaciones protectoras-, extinguir los supuestos depósitos ilegales que tenían algunos cartoneros de la organización y construir la confianza de que van a trabajar si les otorgase la licitación de la basura. La enunciación se da en el nivel de producción de representaciones, operando el texto como una mediación entre la dimensión de lo individual y lo colectivo (Christine Servais: 2013; Pág.1). La enunciación, según la autora tiene una importancia política inmediata pues supone la construcción de un nosotros y otro generalizado.

En este punto resulta interesante por un lado poder visualizar la lectura de medios locales y poder en cierta forma contrarrestarlo con la publicidad de la propia organización sobre los hechos (Harjvard 2008). Se puede afirmar que la lógica mediática ha tendido a simplificar el problema, mas los actores han contribuido a su complejización con sus argumentos y acciones. Algunos medios locales alternativos escucharon la voz de los carreros y militantes dando lugar a la discusión pública, confrontando diferentes puntos de vista. Otros en cambio apuntaron a caracterizar a los cartoneros como conflictivos, sin profundizar en sus demandas, poniendo el eje de la polémica en el caos vehicular y el maltrato animal.

El intendente de La Plata se refirió al corte que realizaron este miércoles organizaciones de carreros y cartoneros frente al Municipio. "Vamos a continuar controlando para evitar que continúen explotando a los caballos" Portal Online Primera Página. 
Poco antes de las 11 de la mañana, un grupo de cartoneros cerró el paso de 12 a 10 y de 50 a 54, generando un embotellamiento que se hizo sentir desde plaza Moreno a plaza San Martín. Una numerosa cantidad de carros con caballos bloqueó el paso de vehículos, y complicó la salida de los alumnos que acuden al colegio San José. Portal online Diario El Día.

El centro platense estuvo cargado de tensión este mediodía por una protesta que desarrollaba la Federación Argentina de Cartoneros, Carreros y Recicladores (FACCYR). Según indicaron los manifestantes, les habían prometido incorporar nuevas cooperativas al listado de destinos sustentables, una acción que en caso de concretarse posibilitará la emisión de certificados de tratamiento un trámite necesario para poder operar y generar puestos de trabajo. Portal online Diario El Día

Repudio a la renovación de contrato de Esur: Un centenar de carreros copó la municipalidad. "Pedimos que el municipio no le deje todo el reciclado a Esur. Quieren extenderles el contrado, pero Esur se está llevando todo el material reciclable y eso perjudica a todos los cartoneros". Portal de noticias Online Realpolitik.

Tras dos años de acciones de protesta el MTE logró la licitación de la Bolsa Verde para cincuentas cartoneros y cartoneras, a fines de 2017 y un presupuesto mensual para el alquiler de un galpón donde funciona actualmente la primera cooperativa auto-gestionada de los cartoneros y cartoneras del MTE.

Retomo brevemente el esquema presentado por Chateauraynaud (2004) para comprender de alguna manera este proceso de mediatización y argumentación que llevo no solo a la instalación del problema en esta ciudad sino a obtener respuestas de los funcionarios.

\begin{tabular}{|l|l|l|}
\hline Argumentación & Instancias de argumentación & Resolución \\
\hline Plano 1 & $\begin{array}{l}\text { Hacia el interior de la organización: } \\
\text { asambleas, debates, capacitaciones, } \\
\text { etc. Mediatización. }\end{array}$ & $\begin{array}{l}\text { A través de la conversación, } \\
\text { el conflicto y el acuerdo. } \\
\text { Promesa }\end{array}$ \\
\hline Plano 2 & $\begin{array}{l}\text { Desde la organización hacia afuera. } \\
\text { Visibilización e instalación de la } \\
\text { problemática. Charlas, campañas, } \\
\text { debates, etc. Mediatización. }\end{array}$ & \begin{tabular}{l} 
Negociación. Contrato. \\
\hline Plano 3
\end{tabular} \\
$\begin{array}{l}\text { Denuncia pública hacia el } \\
\text { municipio, identificación de }\end{array}$ & $\begin{array}{l}\text { Mandato. Licitación pública } \\
\text { de la GIRSU. }\end{array}$ \\
\hline
\end{tabular}

Question, Vol. 1, N. ${ }^{\circ}$ 64, octubre-diciembre 2019. ISSN 1669-6581

Instituto de Investigaciones en Comunicación | Facultad de Periodismo y Comunicación Social | Universidad Nacional de La Plata La Plata | Buenos Aires | Argentina 
demandas, acciones de protesta

y movilización. Mediatización.

En este sentido las acciones colectivas funcionaron como plantea Nardacchione (2005) meta comunicación, denunciando los bloqueos que la gestión municipal interponía al dialogo, logrando restablecerlo y negociar. Claro que este proceso no estuvo exento de tensiones tanto hacia el interior del sujeto colectivo de protesta como hacia afuera.

\section{Reflexiones finales}

El impacto de las acciones y los actores involucrados se dirimieron en la arena pública en su dimensión local. Evidentemente no estoy hablando sobre un evento que se anoticie a grandes escalas sino de un conflicto que se asienta en un espacio público específico.

Es la acción colectiva la que otorgo dignidad al sujeto hablante. De ese sujeto desempleado y marginal capturado por las cámaras que revolvía la basura allá por el 2001 a un sujeto colectivo con una argumentación clara para disputar en la arena pública.

Esas argumentaciones, discursos y estructuras de acción construidas a nivel macro en un colectivo identificado se trasladaron a la reciente experiencia de organización cartonera a nivel de lo local. El proceso de instalación del problema conto con diferentes componentes que abrieron el debate y sostienen sus tensiones.

Por último, presento el siguiente mapa conceptual a manera de visualizar el proceso de reconstrucción del problema público comprendido. Al hablar de re-construcción quisiera instalar la premisa de que ha sido y es la acción colectiva lo que permitió la apropiación de una gramática alternativa a la que presentaron ciertos actores públicos y privados, así como los medios de comunicación.

Red: Construcción de un problema público 


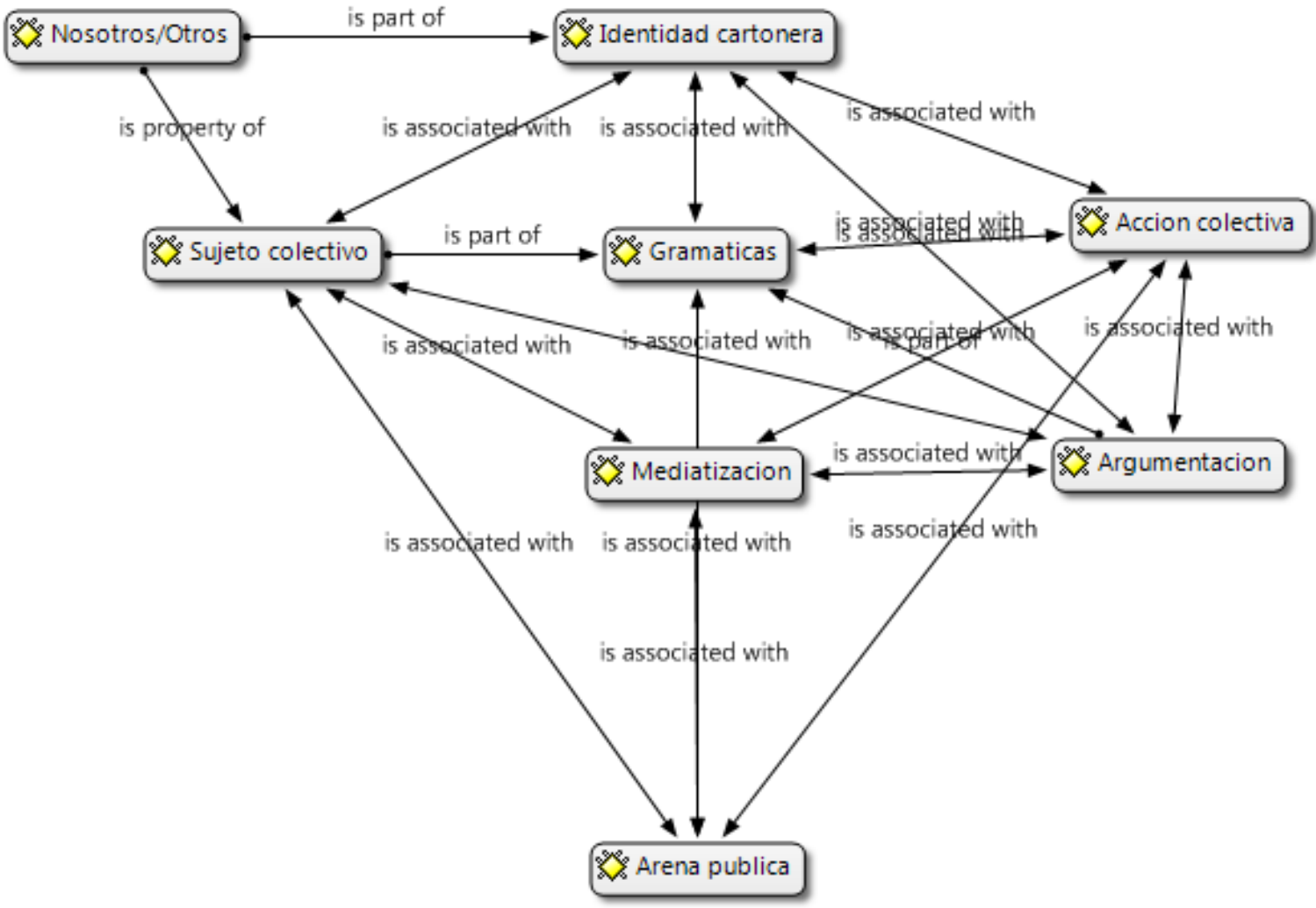

Concibo este proceso a través de la triada IDENTIDAD COLECTIVA-GRAMÁTICA-ACCIÓN COLECTIVA. Lo que se explicita es que es la constitución de una identidad colectiva y de un sujeto colectivo lo que posibilita una gramática que se transforma en argumentos que sostienen la acción colectiva en la arena publica. $Y$ este es siempre un proceso mediatizado y mediatizador. Sin esos discursos y representaciones no es factible llegar a un nivel de acciones que disputen la gestión del conflicto en el espacio público. Para una organización de estas características gestionar el conflicto significa moverse en el plano de las demandas y conquistas que le permiten la subsistencia.

Notas

(1) Sobre esto se constatan archivos periodísticos de diarios cono Clarín, Página 12, La Nación, El día, entre otros y archivos televisivos de diferentes noticieros. Por cuestiones de tiempo y organización no incluyo las fuentes en el cuerpo del trabajo.

(2) El nombre se debe a que la formación era de color blanco, sin ventanas, puertas ni asientos en su interior. En principio tenía tres vagones pero para el año 2007 contaba con siete. 
(3) Sobre los aspectos relativos a la GIRSU, política ambiental y su relación con la actividad cartonera realice un trabajo junto a Inés Cortazzo. En el mismo se develan datos oficiales sobre la gestión de residuos dando cuenta de la ineficiencia del sistema y la reducción del presupuesto municipal mediante el trabajo no remunerado a los recuperadores informales de residuos.

Disponible

en:

http://biblioteca.clacso.edu.ar/clacso/se/20190813110352/Como pensamos las desigualdades .pdf\#page $=67$

(4) Nuclea a los trabajadores cartoneros, carreros, recicladores y recuperadores urbanos de todo el país, organizados en cooperativas u otras formas asociativas. Entre ellas encontramos a la Asociación de cartoneros de Villa Itatí (Quilmes), Cartoneros Unidos de Lanús, Carreros de la Matanza y MTE21 Carreros de La Plata, organización con la que realizamos nuestro estudio en el campo. A nivel nacional, incluye organizaciones en Provincia de Buenos Aires, CABA, Río Cuarto, Tucumán, Santa Fe y Córdoba.

(5) Cabe destacar que el universo cartonero no es un universo homogéneo. Hay quienes se denominan carreros, característicos de utilizar un carro tirado por un caballo, o por tracción a sangre humana. Otro grupo, generalmente aquellos que están cooperativizados, poseen otros recursos (galpones, depósitos, plantas de reciclaje), han aceptado la prohibición de usar caballos para su trabajo y se autodenominan recicladores. La principal actividad es la recuperación en la vía pública y posterior venta.

\section{Bibliografía}

Anguita, E (2003). Cartoneros, recuperadores de desechos y causas perdidas. Buenos Aires. Grupo Editorial Norma.

CEFAÏ, D. Arène publique. Un concept pragmatiste de sphere publique.

Cosaco, N y Perelman, M. (2011) "Modos de apropiación de la ciudad, conflicto y gestión del espacio urbano. La construcción de fronteras en la ciudad de Buenos Aires." en Di Virgilio, M. (et. al.).La cuestión urbana interrogada: transformaciones urbanas, ambientales y políticas públicas en Argentina. Buenos Aires, Argentina. Café de las Ciudades.

Dimarco, M. (2005). Experiencias de auto organización en cartoneros: un acercamiento a la configuración de los vínculos laborales y sociales en contextos de exclusión social. Buenos Aires, Argentina. Programa Nacional de Becas CLACSO. Disponible en: www.bibliotecavirtual.clacso.org.ar 
Gorbán, D. (2014). Las tramas del cartón. Trabajo y familia en los sectores populares. Buenos Aires, Argentina. Prometeo.

Herrero, V. (2016). De espacios, lugares y territorios. Transitar los estigmas de la ciudad: recuperadores no convencionales de residuos urbanos en la ciudad de La Plata. III Foro Latinoamericano de Trabajo Social. Disponible en http://sedici.unlp.edu.ar/handle/10915/64984

Herrero, V. (2017) \& Schettini, P. Cartoneros y recuperadores urbanos de residuos como trabajadores informales organizados: Algunas reflexiones a partir de un estudio en la Ciudad de La Plata. V Seminario Internacional Desigualdad y Movilidad Social en América Latina, 31 de mayo y $1^{\circ}$ y 2 de junio de 2017, Ensenada, Argentina. Disponible en: http://www.memoria.fahce.unlp.edu.ar/trab eventos/ev.10625/ev.10625.pdf

Herrero, V (2018). La intervención social hacia adentro. Una experiencia desde la organización y acción colectiva de los cartoneros del Movimiento de Trabajadores Excluidos en La Plata. Revista Horizontes en intervenciones sociales. Editorial Tesseo. Año 1-№1, pág.27 a 51. ISBN-13: 9789877784626. ISBN-10: 9877784629 Disponible: https://www.editorialteseo.com/archivos/16191/horizontes-en-intervenciones-sociales/

Hjarvard, S (2008): The mediatization of society. A theory of the media as agents of social and cultural change. Nordicom Review 29, (2008) 2, pp. 105- 134.

Nardacchione, G (2005): "La acción colectiva de protesta: del antagonismo al espacio público", en Schuster, Naishtat, Nardacchione y Pereira (comps.): Tomar la palabra. Estudios sobre la protesta social y acción colectiva en la Argentina contemporánea", Buenos Aires, Prometeo.

Menéndez, N. (2013). Del taller a la asamblea. Reflexiones sobre las transformaciones de un colectivo laboral a partir de una experiencia de Investigación- acción participante. Enfoques XXV, 1 .Versión On-line ISSN 1669-2721.Editorial UAP, Universidad Adventista del Plata.

Schamber, P y Suaréz, F (Comp.). (2007). Recicloscopio. Miradas sobre recuperadores urbanos en América latina. Tomo I. Buenos Aires, Argentina. UNGS - Ciccus.

Schamber, P y Suaréz, F (Comp.). (2011).Recicloscopio. Miradas sobre recuperadores urbanos, políticas públicas y subjetividades en América latina. Tomo II. Buenos Aires, Argentina. UNGS - Ciccus.

Servais, C (2013). Versión traducida por M. Fernández, y adaptada para su uso exclusivo en la cursada de la cátedra 1 de Comunicación y Cultura (FPyCS, UNLP). Título del original: 
«Énonciation journalistique et espace public », Communication[En ligne], Vol. 32/2 | 2013

Tarrow, S. (1997).El poder en movimiento. Los movimientos sociales, la acción colectiva y la política. Madrid, España. Alianza editorial.

Verón, E (1998): "Mediatización de lo político. Estrategias, actores y construcción de colectivos", en Mouchon, Gauthier (comps): Comunicación y política. Barcelona. Gedisa

Verón, E (1999): "Destinatarios", en Efectos de Agenda. Barcelona. Gedisa.

Villanova, N. (2015) Cirujas, cartoneros y empresarios. La población sobrante como base para la industria papelera. Buenos Aires, Argentina. Ediciones RYR.

\section{Fuentes periodísticas}

Repudio a la renovación de contrato de Esur. Un centenar de carreros copó la municipalidad. Portal de noticias Online Realpolitik. (30 de junio de 2017). Recuperado de: https://realpolitik.com.ar/nota/28424/repudio a la renovacion de contrato de esur u n centenar de carreros copo la municipalidad/

Protesta de cartoneros y enorme caos vial. Portal online Diario El Día. (10 de mayo de 2017) Recuperado de https://www.eldia.com/nota/2017-5-10-2-50-37-protesta-de-cartonerosy-enorme-caos-vial-en-la-zona-de-la-plaza-moreno-la-ciudad

https://www.eldia.com/nota/2017-10-29-4-0-55-como-sera-el-codigo-de-convivencia-parafrenar-el-caos-urbano-en-la-ciudad-informacion-general

Garro vs cartoneros por la tracción a sangre. (18 de octubre 2018). Portal Primera Página. Recuperado de: http://primerapagina.info/2018/10/19/garro-vs-cartoneros-por-latraccion-a-sangre/

Por cortes y manifestaciones la ciudad volvió a ser un caos. Portal online Diario El Día. (6 de diciembre de 2017).Recuperado de:https://www.eldia.com/nota/2017-12-6-13-0-42corte-en-11-entre-50-y-54-por-manifestacion-de-cartoneros-la-ciudad

No habrá más tren blanco hacia el norte. Portal Online Página 12. (15 de agosto 2017). Recuperado de https://www.pagina12.com.ar/diario/ultimas/20-89731-2007-08-15.html

\section{Páginas consultadas}

Federación Argentina de Cartonero y Recicladores (FACyR).http:/facyr.org.ar/tag/carreros/ Confederación de Trabajadores de la Economía Popular (CTEP) http://ctepargentina.org/ 
Facebook: MTE La Plata, Berisso, Ensenada. Recuperado: https://www.facebook.com/mtelaplata/

\section{Documental}

Cartoneros de Villa Itatí (2003). Dirección: Ana Cacopardo, Eduardo Mignogna, Ingrid Jaschek, Andrés Irigoyen y Pablo Spinelli 